Background Casual sex among travellers is common. It is unknown whether travellers use condoms differently with local versus western casual partners when visiting HIV endemic areas. We determined the number of casual sexual partners and consistency of condom use among Dutch long-term, non-expatriate travellers to (sub)tropical regions according to the ethnicity of their casual sexual partners, and estimated the incidence of HIV and syphilis on their return.

Methods A prospective mono-centre study of Dutch long-term travellers $\geq 18$ years, attending the Public Health Service travel clinic in Amsterdam (2008-2011) and travelling to any (sub)tropical country for $\geq 12$ and $\leq 52$ weeks, was conducted. Travelers reported their travel purpose, duration, destinations(s), number and nature of sexual contacts while travelling: ethnicity, gender, partner type (steady/casual) and consistency of condom use with each partner. Analyses were conducted using Poisson regression (generalised estimating equations to account for multiple partnerships). Blood samples, taken before and after travel, were tested for HIV and Treponema-pallidum antibodies.

Results There were 552 respondents and 11671 person-weeks of follow up (median age: 25 years, $36 \%$ male, median travel time: 20 weeks, $45 \%$ for work/study). Post travel, $34 \%(\mathrm{n}=190 / 552)$ reported $\geq 1$ casual sexual partner, men a median of 3 (range:1-8) and women 2 (range:1-7) partners. Of 462 casual sexual partnerships, 42\%(n=192) were with local partners at travel destination. Equally, 39\% of partnerships with western and local partners were unprotected. Single travellers (IRR steady partner(ref) $: 2.95 \% \mathrm{CI}: 1.2-4.0)$ and those on holiday $\left(I_{\text {work/study (ref) }}: 1.9 .95 \%\right.$ CI: $\left.1.2-3.0\right)$ had more unprotected casual sex. Partner's ethnicity was not significant in predicting condom use. No HIV or syphilis seroconversions were recorded.

Conclusion Unprotected casual sex was common among Dutch long-term travellers, occasionally with multiple local partners in HIV-endemic regions. Single travellers and those travelling for holiday purposes were most at risk. These groups should be advised on the need for safe sex while abroad.

\section{P4.089 REDUCE THE RISK AND VULNERABILITY TO HIV}

doi:10.1136/sextrans-2013-051184.0987

P Enyan. University of Ghana, Accra, Ghana

Background Before the people can reduce the risk and vulnerability to HIV, individuals and communities must understand the urgency to the epidemic. They must be given basic facts about HIV/ aids, taught set of protective skills and offered access to appropriate services and products.

Methods A cross sectional community based survey have been conducted between January 2011 to April 2011 by interview of 419 heads of the households regarding the knowledge of HIV transmission means in Accra, Ghana

Results Out of the interviewed 419 household heads,287(68.5\%) were females. $36 \%, 28 \%$ and $34.3 \%$ were in the age group of $40+, 31-$ 40 and15-30 respectively. The findings revealed that only21(5\%)of study participants mentioned four ways of HIV transmission(unprotected sex, mother to child, sharp materials and blood transfusion). On the other hand,63(15\%) mentioned any three of the above route of transmission, whereas the majority, $209(50 \%)$ and $86(20.5 \%)$ mentioned two and one means of HIV respectively. On contrary about $40(10 \%)$ of interviewed heads of house hold mentioned hardly any of the transmission means. Males were about 2.4 times more likely to mention unprotected sex as one means of transmission than females

Conclusion In general, knowledge of residents of Medina in the capital town of Ghana about HIV transmission and prevention means was low. Appropriate HIV/Aids education means ought to be tailored to residents

\section{P4.090 REMINDERS REMAIN THE BEST CLIENT DRIVEN ADHERENCE COPING STRATEGY FOR THOSE TAKING LIFELONG ON ANTI RETRO VIRAL THERAPY (ART)-THE AIDS SUPPORT ORGANIZATION (TASO) OPERATIONAL RESEARCH FINDINGS}

doi:10.1136/sextrans-2013-051184.0988

A Kawuba, M Denis, K Nathan, N Faridah, M Shafik. The AIDS Support Organization, Kampala, Uganda

Background For one to register ART success, good adherence is of utmost importance. With Art paradigm shift clients face a number of challenges in the long term that requires long term strategies for success.

A study to assess the major ART adherence coping strategies among clients enrolled on treatment with a four years and above experience was conducted.

Method This was a cross sectional study by design using semi structured questionnaires. Data was analysed using logistic regression model. Convenient sampling targeting a total of 400 TASO clients aged 18 years and above, with over four years experience on ART first line Regimen.

Results A total of 400 clients were interviewed and $43 \%$ coped by using reminders, $0.3 \%$ by their times of brushing their teeth, $7.5 \%$ by before and after morning and evening prayers, $1 \%$ by counsellors support, $9.5 \%$ by their medicine companions and $38.8 \%$ had this as a habit.

Conclusion Majority of the clients use reminders for good adherence in the long term. Baseline adherence preparation is very important since it directly leads to development of positive adherence habits.

\section{P4.091 SEXUAL ATTITUDE, CONDOM USE AND ACCESS AMONG YOUNG REFUGEES IN ORU REFUGEE CAMP NIGERIA}

doi:10.1136/sextrans-2013-051184.0989

F 0 Agbaje, 0 A Folayan, NI Ifionu. OROL Youth Empowerment Initiative, Lagos, Nigeria

Background Act of violence committed against young girls in refugee camps may increase susceptibility to HIV and this is due sexual gender- based violence such as psychological abuse and discriminatory practises. The girls are forced to have sex with boys without condoms because of lack of household and decision making power. This Study explored the perception, knowledge, access and consistent use of condoms among young refugees and we hypothesised that there exit a significant relationship between them.

Methods Adolescent refugees ( $n=187.13-19$ years of age)from simple and stratified sample in Oru Refugee camp completed a self -administered questionnaire and focus group discussion was conducted differently for boys and girls between October and December 2008. We performed the analysis using SPSS and frequency distribution was also used.

Results The study shows that $52.4 \%$ of the respondents are female and $47.6 \%$ of them are Male. $56.7 \%$ of the refugees know of a place where one can get condom still about half of the girls did not use condom at their last sex because their partner will not allow and also because of discrimination. Chi-square test was used to compare their access to condom and use of condom which shows a significant relationship between them (Chi value $=39.724, \mathrm{DF}=1, \mathrm{P}$ value $=0.000<0.05$ )

Conclusions The result shows that the young refugees are at risk of getting infected with HIV especially the female ones. The focus group shows that half of the female refugees reported that their partner will not allow them to use condom. The young girls need to be empowered on how to negotiate condom use with their partners. It is also necessary to achieve behavioural change communication 